\title{
Interferon Therapy For Elderly Egyptian Patients With Chronic Hepatitis C of Genotype 4
}

\author{
Mohammed Emam ${ }^{1}$, Waleed A. Abd El-Dayem ${ }^{1}$, Soha AElhawari ${ }^{1}$, \\ Hayam Heeba ${ }^{2}$, Amany Emara ${ }^{3}$ \\ ${ }^{1}$ Tropical Medicine Department, Faculty of Medicine, Zagazig University, Egypt. \\ 2 Internal Medicine Department,Faculty of Medicine, Ain Shams University, Egypt. \\ ${ }^{3}$ Clinical Pathology Department,Faculty of Medicine, Ain Shams University, Egypt.
}

Corresponding author: Mohammed Emam

email:

rana40emo90@yahoo.com mobile:

0020122367100

Received :5 / $11 / 2011$

Accepted after

revision: $29 / 11 / 2011$

Keywords :HCV ;elderly;interferon
Background and study aim: Hepatitis C (HCV) affects nearly one in every 5 Egyptians which is the highest incidence allover the world. Most of the Egyptian Chronic Hepatitis (CHC) patients are of genotype 4 where it represents $90 \%$ of all Egyptian HCV cases. The clinical utility of antiviral therapy in elderly patients in our locality is not clear, also little information is available in literatures allover the world on treatment of such group of patients with genotype 4 . The present study aimed at evaluating the efficacy and safety of combination therapy (pegylated interferon alpha 2a (PegIFN-alph2a) and ribavirin) in treatment of elderly Egyptian patients with HCV genotype 4.

Patients and Methods: 60 elderly Egyptian patients (more than 55years) with chronic HCV (group 1) and another group of 72 younger (less than 55 years) age patients (group 2) were enrolled in the present study. Both group of patients were compensated and all of genotype 4 . Both groups received $180 \mathrm{mcg}$ PegIFNalpha2a subcutaneously once weekly and ribavirin (1000-1200mg/daily) for 48 weeks. Patients were followed for 48 week and sustained virological response and safety were assessed in both group.

Results: A significant improvement in both end of treatment response (ETR) and sustained virologic response (SVR) was noted in both group, where ETR was achieved in $32(53.3 \%)$ and 41 patients (56.9\%) in both groups respectively, and 27 patients in group $1(45.0 \%)$ and 38 $(52.8 \%)$ in group 2 could retain negative viraemia SVR by the end of follow up period. SVR showed a non-significant negative correlation with age. Viral clearance after 4 weeks of therapy was associated with high incidence of ETR and SVR ( $\mathrm{P}<0.001)$, but without significant difference between both group. Rate of discontinuation and periods of discontinuation and side effect and safety was not significantly different in both groups.

Conclusion: : Despite these challenges, the present study showed that $\mathrm{HCV}$ treatment was generally well tolerated by the elderly Egyptian patients (55-68 years) with a little or no significant difference in SVR as well as therapy discontinuation rates secondary to adverse effects compared to younger age groups. Therefore, we recommend that chronic HCV Egyptian patients of age 55 years and more should be included in trials of chronic hepatitis $\mathrm{C}$ treatment and old age is no more contraindication for interferon/ribavirin therapy and the riskbenefit of antiviral therapy should be assessed on an individual basis.

\section{INTRODUCTION}

The World Health Organization has declared hepatitis $\mathrm{C}$ a global health problem, with approximately $3 \%$ of the world's population (roughly 170200 million people) infected with HCV. In the US, approximately 3 million people are chronically infected, many of whom are still undiagnosed[1]. In Egypt the situation is quite worse. Egypt has a population of 80 million and contains the highest prevalence of hepatitis $\mathrm{C}$ in the world. The national prevalence rate of $\mathrm{HCV}$ antibody positivity has been estimated to be between 10-13\%[2]. Hepatitis C 
affects nearly one in every 5 Egyptians which is highest prevalence all over the world .Most of Egyptian HCV patients are of gentype 4 where it represents $90 \%$ of all Egyptian HCV cases [3]. Genotype 4 is one of the neglected hepatitis C virus allover the world[4]. In our locality elderly patients with chronic HCV infection have been an understudied population due to several factors. These factors include exclusion of subjects older than 55 years of age from governmental programs of treatment, shortage of financial support, reluctance to treat $\mathrm{HCV}$ infection in the elderly due to fear of dealing with more HCV therapy related adverse effects, co- morbidities and risk factors of aging.

In Egypt anti-schistosomal injection therapy was the main cause of contamination, followed by procedures performed by informal providers and traditional healers such as dental care, wound treatment, circumcision, and deliveries. CHC is also highly prevalent in sub-Saharan Africa and in the Middle East. In Europe, its prevalence has recently increased particularly among intravenous drug users and in immigrants[4]. Chronic HCV is the main cause of liver cirrhosis and liver cancer in Egypt and, indeed, one of the top five leading causes of death[5]. Preliminary evidence suggests that genotype 4 hepatitis C infection may place the patient at greater risk for hepatocellular carcinoma more than other $\mathrm{HCV}$ genotypes. Despite the decrease in the incidence of acute hepatitis $\mathrm{C}$, the prevalence of longstanding chronic hepatitis $\mathrm{C}$ infection is increasing among older adults[6]. Prevalence of $\mathrm{HCV}$ infection in elderly patients are variable allover the world, in a study that was done in Italy among 496 elderly with a mean age of 79.31 years old, the prevalence of positive $\mathrm{HCV}$ antibody was found to be around 11\%[7]. A study from Japan revealed $8.8 \%$ and $13.1 \%$ of HCV antibody seropositivity in hospital and autopsy cases older than 60 years of age, respectively[8]. However no much data are available for the prevalence of $\mathrm{CHC}$ in elderly patients in Egypt. However Sayed et al.[9] reported that the highest prevalence rates in Egypt were seen in patients between 55-65 years old. The age at the time of infection was significantly associated with the development of cirrhosis[7]. The median time from the age of infection to the onset of cirrhosis that was 33 years in patients who acquired the HCV infection at the age of 21 to 30 was reported to decrease to 16 years in patients who had the infection after the age of 40[10]. The mean time from the age of blood transfusion to the development of cirrhosis was reported to be 9.8 years in patients who had blood transfusion at the age of 50 or more. Also investigators from Japan reported a significantly shorter interval between the time of blood transfusion and the diagnosis of $\mathrm{HCV}$-associated hepatocellular carcinoma if the blood transfusion was received at an older age[8].

The hepatitis $\mathrm{C}$ virus (HCV) genotype is one of the main predictors of response to interferon (IFN)-based therapies. Information about treatment response of $\mathrm{HCV}$ genotype 4 patients is scarce and conflicting results have been reported[13].

Although the safety and efficacy of hepatitis C therapies have been extensively studied in patients between ages of 18 and 60 , patients who are over 65 still remain understudied and difficult to treat population. Some past research indicates that older individuals do not respond as well to interferon-based therapy, but data are inconsistent. Adverse effects of antiviral therapy are more prevalent in elderly patients (age $\geq 60$ years) with chronic hepatitis $\mathrm{C}$ (CHC) than in their younger counterparts, and often interrupt or halt their treatment. Interferon and ribavirin treatment is, therefore, considered to have reduced efficacy in this group[14]. Elderly patients with $\mathrm{CHC}$, however, have an increased risk of developing hepatocellular carcinoma, and antiviral therapy is an effective way of reducing this risk and improving survival. However, the clinical utility of antiviral therapy in elderly patients is not clear and little information is available on their prognosis, with or without such therapy. Canadian consensus guidelines recommended that old age more than 65 years is no more contraindication for interferon/ ribavirin therapy[15]. In Egypt nearly no data are available about combination (interferon/ribavirin) therapy for this group of patients with $\mathrm{HCV}$ of genotype 4 as elderly patients are out of treating governmental programs due to shortage of financial support, reluctance to treat $\mathrm{HCV}$ infection in the elderly due to fear of dealing with more HCV therapy related adverse effects, co morbidities and risk factors of aging. The purpose of the present study was to study the effectiveness and safety of IFN- $\alpha 2 \mathrm{a}$ (Pegasys, $180 \mathrm{mcg}$ ) once weekly in combination with ribavirin, in elderly Egyptian compensated HCV patients of genotype 4. 


\section{PATIENTS AND METHODS}

Detailed Description : A prospective, multicenters, case- control study conducted in Tropical Medicine Department, Zagazig University, Egypt and Riyadh National Hospital (RNH) (KSA) enrolling 60 Egyptian patients with chronic hepatitis $\mathrm{C}$ of genotype 4 who are 55 to 68 years of age (group 1) and other sexand HCV genotype-matched 72 chronic hepatitis C Egyptian patients who are 22 to 54 years of age (group 2) conducted for comparison. Most of patients in RNH group were of old age those patients entered KSA before the obligatory preemployment $\mathrm{HCV}$ examination starting since 15 years. All patients received pegylated interferonalpha 2a (PEGASYS®) $180 \mathrm{mcg} /$ week and Ribavirin 1000-1200 mg/day, the combination therapy given for 48 weeks of treatment. The primary outcome measurement was sustained virological response and safety of treatment in both studied groups. Secondary Outcome Measures, rapid virological response (RVR), defined as HCV RNA $<15 \mathrm{IU} / \mathrm{mL}$ at week 4 treatment.

Inclusion Criteria: Patients have never been treated with traditional interferon plus ribavirin or peginterferon plus ribavirin. the patient were subjected to the following:

- Serologic evidence of chronic hepatitis C infection by an anti-HCV antibody test (performed using a third-generation enzyme immunoassay (MEIA; Abbott Laboratories, Abbott Park, IL, USA).

- Detectable serum HCV-RNA was assessed both qualitatively (COBAS AMPLICOR-HCV Test, v2.0; Roche Diagnostics; lower limit of detection $50 \mathrm{IU} / \mathrm{mL}$ ) and quantitatively (COBAS AMPLICOR-HCV MONITOR Test, v2.0, Roche Diagnostics, lower limit of quantitation $15 \mathrm{IU} / \mathrm{mL}$ ).

- HCV genotype was determined in all patients by using hybridisation techniques (Innolipa $\mathrm{HCV}$, Bayer).

- Liver biopsy findings consistent with the diagnosis of chronic hepatitis $\mathrm{C}$ infection with compensated cirrhosis (Exception: patients with bleeding tendency in whom biopsy is medically contra-indicated and patients more than 60 years do not require biopsy).

- Compensated liver disease (Child-Pugh Grade A classification) with no history of esophageal Varices, Ascites and /encephalopathy.

- Measuring of serum TSH, AFP and ANA.
- Negative urine or blood pregnancy test (for women of childbearing potential) documented within the 24-hour period prior to the first dose of study drug.

- All fertile males and females receiving ribavirin must be using two forms of effective contraception during treatment and for six months after treatment end.

- Patient consent was obtained.

Exclusion Criteria : Patients were excluded from the treatment protocol if they had any of the following well-known contra-indications to antiviral therapy: If the patient is classified as child $\mathrm{B}$ or $\mathrm{C}$ chronic liver disease, haemoglobin $<12 \mathrm{~g} / \mathrm{dL}$, white blood cells $<4000 \mathrm{cell} / \mathrm{mm} 3$ (neutrophil count $<2000 / \mathrm{mm} 3$ ), platelet count $<100,000$ cells/ mm3, concomitant antibodies (ANA, AMA and ASMA positive), psychiatric disorders, infection with the human immunodeficiency virus, HBV positive patients, alcohol and/or drug abuse, severe cardiac or pulmonary disease. Also patients who are not responding at week 12 should stop treatment. All patients had normal thyroid function prior to the study. Patients with a creatinine clearance of $<50$ $\mathrm{mL} /$ minwere excluded form the study as ribaverin should not given in this cases.

Follow up : all patients were followed up for 48 weeks. Hematological parameters were assessed every 2 week for the first 8 weeks of treatment and patients underwent a complete blood count on a monthly basis. HCV RNA assessments (both qualitative and quantitative) were performed at weeks 4, 12 and 24 weeks and at the end of treatment. The dose modifications and the cause of treatment tailoring or stopping, where appropriate. The study endpoint in virological response includes : (1) 48 weeks negativity defined as undetectable serum $\mathrm{HCV}$ RNA after a 48 week of treatment, (2) SVR, defined as undetectable serum HCV RNA after a six months untreated follow-up period.

\section{Statistical analysis :}

Data were expressed as mean \pm standard deviation or number and percentage. Data were compared using Chi-square test or Fisher's exact, t- test when appropriate. P-value less than 0.05 were considered statistically significant.

\section{RESULTS}

This study was conducted in Department of Tropical Medicine, Zagazig University in Egypt and RNH hospital in KSA. The conducted study involving 132 chronic HCV Egyptian patients 
between December 2007 and May 2011. the patients were classified into two groups: 60 patients older than 55 years old (group1),and 72 patients younger than 55years of age(group 2) .All scheduled for 48 weeks of combination therapy with interferon and ribavirin. Baseline demographic (apart form age) data and disease characteristics were similar in both groups (Table 1)

The age of acquisition of infection and mode of infection can not defined exactly in both studied groups, however, the suspected duration of infection was significantly higher in old age group. Also history of blood transfusion, surgical, dental sable anti bilharzial treatment were reported more in old age patients.

One hundred twenty-four patients out of 132 completed the study and follow up periods. Five patients $(8.3 \%)$ Of the elderly patients, had to discontinue therapy due to adverse effects such as severe thrombocytopenia and low white blood cell retinal hemorrhage. In the same group, 8 patients $(13.3 \%)$ had to adjust or tailor treatment due to laboratory abnormalities, while in the younger age group only $4(5.6 \%)$ and $9(12.5 \%)$ of patient had to discontinue and adjust the treatment due to side effect and abnormal laboratory finding respectively. The discontinuation more than 10 weeks occurred in $10(16.7 \%)$ and $8(11.1 \%)$ patient in both groups respectively.

The viral load was significantly higher in old age grouping comparison to younger age group. In intent-to-treat analysis, the sustained virological response (SVR) rate was "substantially lower" for the older compared with the middle-aged group ( $45 \%$ vs. $52.8 \%$, respectively), but the difference did not reach statistical significance $(\mathrm{P}$ $=0.88$ ) The prevalence of adverse effects due to IFN therapy, especially lethargy, confusion, and changes in behavior, was higher for older patients.

Among older patients who experienced a rapid virological response at week 4 of treatment and received treatment for $>80 \%$ of the duration of the treatment course, the SVR was responding at week 4 higher in those patients who $\mathrm{r}$ similar to those of younger age group (45\% vs $52.8 \%$, respectively) $(\mathrm{p}=0.37)$. The older group had a higher rate of treatment discontinuation but not significant compared with the middle-aged group $(8.3 \%$ vs $5.6 \%$, respectively; $\mathrm{P}=0.77)$. The hematologic adverse events were the most common encountered adverse effects. There are three major problems encountered: neutropenia, thrombocytopenia, and anemia.

Neutropenia : Patients of both group showed significant neutropenia approximately 3-6 times during monthly follow up visits. Dose reductions occurred in 16 of individuals less than 55 years. Older patients were noted to have dose modifications for neutropenia in 12 patients'. The severity of neutropenia was higher in old age group than the younger group. It was the cause of stopping treatment in 3 patients in old age group and two patients in younger age group. Currently, dose reduction was the only management for neutropenia, no one in both groups has used GCSF.

Thrombocytopenia: 14 and 11 of patients in both group respectively needed reductions of treatment for thrombocytopenia during study. Dose reduction was recommended when platelet counts fall below 50,000. Two patients in old age group discontinued treatment due to sever thrombocytopenia. Discontinuation of therapy was recommended if platelet counts fell below 30,000 .

Anemia: 23 and 34 patients in both group respectively experienced anemia (mild to moderate). Management of anemia was to reduce ribavirin dose for hemoglobin less than $10 \mathrm{~g} / \mathrm{dl}$, and obtain blood count levels every two weeks or more frequently. Ribavirin dosing was recommended to be discontinued in 4 patients in elderly group and only one patient in younger age group when hemoglobin falls below $8.5 \mathrm{~g} / \mathrm{dl}$. One patient in both groups were given erythropoietin [epoetin-alfa (Eprex, Janssen Cilag S.p.A)] at 40,000 international units weekly for few weeks (6-9 weeks) which significantly improves hemoglobin.

A regression analysis of sustained virologic response rate and ribavirin dosage shows a clear direct relationship between SVR and dose, that full dose scheduling of ribavirin permits virologic responders to have an ultimate SVR. Dose reduction results in a fall to $52.8 \%$ of younger age group compared to $45.09 \%$ in older age group individuals.

Intent to treat (ITT) analysis showed significant improvement in both of ETR and SVR with pegIFN therapy, where ETR was $53.3 \%$ and $56.9 \%$, respectively, while SVR was $45.09 \%$ and $52.8 \%$ $(\mathrm{P}<0.37)$.

Regarding viraemia, there was a significant difference between responders and non- 
responders in both groups and within the same group. Viral clearance after 4weeks of therapy was associated with high incidence of ETR and SVR $(\mathrm{P}<0.6)$, but also without significant difference between both groups. Six patients in old age group and two in the other group could not continue the study due to sever side effects, which was of significant difference.
27 out of 34 old age patients who showed rapid virologic response maintained sustained virologic response, while 38 patients out of 44 showed the same response in younger age patients (Table 2).

Table (1) : Demographic, clinical and biochemical characteristics in both groups

\begin{tabular}{|c|c|c|c|}
\hline & Group $1(n=60)$ & Group $2(n=72)$ & $\mathbf{P}$ \\
\hline Age (years) & $58.4 \pm 7.5$ & $43.2 \pm 7.6$ & $<0.001 * *$ \\
\hline Sex : Male & $54(90.0 \%)$ & $57(79.2 \%)$ & 0.09 \\
\hline Female & $6 \quad(10.0 \%)$ & $15(20.8 \%)$ & NS \\
\hline HCV RNA IU/ml & $387.262 \pm 167.854$ & $316.923 \pm 154.849$ & $<0.05^{*}$ \\
\hline ALT $<2$ upper limit of normal n (\%) & $51(85.0 \%)$ & $58(80.5 \%)$ & $0.05^{*}$ \\
\hline Suspected Duration of HCV infection (years) & $26.4 \pm 6.5$ & $12.8 \pm 4.3$ & $<0.001 *$ \\
\hline Platelet count $(1000 / \mu \mathrm{l})$ & $135.28 \pm 49.7$ & $146.2 \pm 52.8$ & $>0.05$ \\
\hline Hemoglobin (g/dL) & $11.87 \pm 2.5$ & $13.20 \pm 1.5$ & $<0.001 *$ \\
\hline Absolute neutrophil count (cells $/ \mu \mathrm{l})$ & $1584 \pm 189$ & $1615 \pm 164$ & $\begin{array}{l}>0.05 \\
\mathrm{NS}\end{array}$ \\
\hline $\begin{array}{l}\text { Discontinuation of treatment owing to adverse } \\
\text { effects }\end{array}$ & $5(8.3 \%)$ & $4 \quad(5.6 \%)$ & $\begin{array}{l}0.77 \\
\mathrm{NS}\end{array}$ \\
\hline $\begin{array}{l}\text { Modification of treatment owing to laboratory } \\
\text { abnormalities }\end{array}$ & $8(13.3 \%)$ & $9(12.5 \%)$ & $\begin{array}{l}0.88 \\
\mathrm{NS} \\
\end{array}$ \\
\hline $\begin{array}{c}\text { Weeks of discontinuations } \\
\text { 1. Less than } 10 \text { weeks } \\
\text { 2. More than } 10 \text { weeks }\end{array}$ & $\begin{array}{cc}10 & (16.7 \%) \\
2 & (3.3 \%) \\
\end{array}$ & $\begin{array}{cc}8 & (11.1 \%) \\
1 & (1.4 \%) \\
\end{array}$ & $\begin{array}{l}0.35 \mathrm{NS} \\
0.87 \mathrm{NS}\end{array}$ \\
\hline $\begin{array}{l}\text { Dose reduction due to : } \\
\text { Neutropenia } \\
\text { Thrombocytopenia } \\
\text { Anemia }\end{array}$ & $\begin{array}{ll}12 & (20.0 \%) \\
14 & (23.3 \%) \\
23 & (38.3 \%)\end{array}$ & $\begin{array}{ll}16 & (22.2 \%) \\
11 & (15.3 \%) \\
34 & (47.2 \%)\end{array}$ & $\begin{array}{l}0.75 \mathrm{NS} \\
0.23 \mathrm{NS} \\
0.3 \mathrm{NS}\end{array}$ \\
\hline Number of patients could not continue the study & $6(9.9 \%)$ & $2(2.8 \%)$ & $<0.001 *$ \\
\hline
\end{tabular}

$* \mathrm{P}<0.05$ (significant)

N S : non significant

Table (2): Virological response in both group.

\begin{tabular}{|l|c|c|c|}
\hline & $\begin{array}{c}\text { Group 1 } \\
(\mathbf{n = ~ 6 0 )}\end{array}$ & $\begin{array}{c}\text { Group 2 } \\
(\mathbf{n}=\mathbf{7 2})\end{array}$ & P \\
\hline 4 week response (RVR) & $34 / 60(56.7 \%)$ & $44 / 72(61.1 \%)$ & $0.6 \mathrm{NS}$ \\
\hline 48 week response (ETR) & $32 / 60(53.3 \%)$ & $41 / 72(56.9 \%)$ & $0.67 \mathrm{NS}$ \\
\hline Sustained virological response (SVR) & $27 / 60(45.0 \%)$ & $38 / 72(52.8 \%)$ & $0.37 \mathrm{NS}$ \\
\hline
\end{tabular}

\section{DISCUSSION}

During the past decade, our knowledge of the pathogenesis, clinical course, and treatment of chronic hepatitis $\mathrm{C}$ virus (HCV) infection has increased tremendously. Chronic infection is prevalent and may be more severe in the elderly population. It is estimated that physicians will be encountering increasing numbers of elderly persons with liver diseases due to chronic $\mathrm{HCV}$ infection. However, there are hardly any data on the various aspects of pathogenesis and treatment of the disease in old age [17]. The aim of this article was evaluation the of efficacy and safety of the standard combination therapy in chronic HCV Egyptian elderly patient (age, more than
55 years) and to suggest an approach to management of the infection in this population.

The mechanisms underlying the relatively rapid progression of liver disease in older patient are not known. Most of the older adults with chronic hepatitis $\mathrm{C}$ virus infection acquired the disease earlier in life. These patients often present with complications of liver disease, mainly cirrhosis and hepatocellular carcinoma. The burden of chronic hepatitis $\mathrm{C}$ virus infection in elderly persons is expected to increase significantly in our locality in Egypt during the next 2 decades.

There are few clinical studies conducted in HCV-positive elderly patients especially in HCV 
patients genotype 4. One of the major reasons for this could be the exclusion of subjects who were 55 years or older in HCV related clinical studies[16-18]. In several randomized trials, the mean age was reported to be around 40 years[1921]. Other reasons for exclusion of older participants could be the increased co-morbid conditions at older age, the fear of facing more adverse effects during the $\mathrm{HCV}$ treatment, or reluctance to perform liver biopsies in the elderly. In Egypt ,patients more than 55 years old are out of governmental programs for $\mathrm{HCV}$ treatment, and nearly no studies were conducted on these a group in our country.

The mechanisms underlying the relatively rapid progression of liver disease in older adults are not known. Possible mechanisms for the role of aging in fibrosis progression are higher vulnerability to environmental factors (especially oxidative stress)[18], reduction in the rate of hepatic blood flow, and reduced mitochondrial capacity[19,20], as well as impaired immunity, may explain the significantly higher viremic load in older patients[16].

The current standard of care for HCV infection is pegylated IFN- $\alpha$ and oral ribavirin[16,30]. The goal of antiviral treatment is to prevent complications of the disease, mainly cirrhosis and HCC. We propose that, for all older patients, treatment decisions should be individualized on the basis of the severity of the liver disease, potential for serious adverse effects, likelihood of treatment response, and presence of comorbid conditions. Therapy is contraindicated for patients with decreased life expectancy due to severe hypertension, heart failure, or coronary artery disease; poorly controlled diabetes; or obstructive lung disease[16]. Chest radiography and electro-cardiography are prudent to exclude significant pulmonary and cardiac disease that may be exacerbated by ribavirin-associated anemia[36]. We believe that, owing to the higher risk of adverse effects from antiviral treatment for elderly persons, the degree of liver fibrosis should be assessed before consideration of therapy. There are only a few, nonrandomized studies on treatment of $\mathrm{HCV}$ infection in elderly patients. Early reports did not assess the rate of sustained virologic response[19-22].

A study in France comparing chronic HCV infection in patients more than 65 years of age with that in younger patients demonstrated that the older group had a significantly longer duration of infection (26 vs. 20 years), a higher age at infection (50 vs. 24 years) and increased likelihood of a history of transfusion (51\% [449 of 881] vs. 29\% [957 of 3301])[23], this also was in agreement with the present study where the suspected duration of infection was higher in our old age group. Among persons who underwent liver biopsy, the fibrosis stage was higher for those aged 65 years, regardless of infection duration.

A different message derives from a populationbased study in Italy of adults aged 60 years[24]. Although $4.1 \%$ of the participants (44 of 1063) had HCV antibodies, only 54.3\% (19 of 35 antiHCV-positive persons studied) had HCV viremia, all of whom were either asymptomatic or had mild liver disease. The discrepancy between these studies may be due to the differing characteristics of the study populations. The first population consisted only of patients referred for treatment, whereas the second was community based and included all individuals with $\mathrm{HCV}$ antibodies. It may be that many older patients had either recovered from the disease or were asymptomatic carriers.

The efficacy of therapy with IFN (or pegylated IFN) and ribavirin in older adults was reported in 2 small case series. Among 20 patients $>65$ years of age, the rate of sustained virologic response was $45 \%$ (9 patients)[29], and among 30 patients with a mean age of 65 years, $30 \%$ (9 patients) achieved a sustained response[28]. The rate of sustained virologic response reported for younger populations treated with pegylated IFN and ribavirin is, on average, 55\%[29-30], this results were also in accordences with our results for both old age and younger age group.

It seems important that, for elderly patients with chronic hepatitis $\mathrm{C}$, the risk-benefit of combination antiviral therapy consisting of pegylated interferon and ribavirin should be assessed on an individual basis. Assessment should be performed in all cases before considering treatment, and it should include evaluation of the degree of liver fibrosis by means of liver biopsy or, possibly, by means of noninvasive methods.However, there is a need for prospective randomized controlled trials to be conducted in HCV Egyptian patients older than 68 years of age for better evaluation of the safety and efficacy of $\mathrm{HCV}$ treatment in this age group[25]. In addition, more epidemiologic studies are needed for better assessment of the prevalence as well as the risk factors of chronic HCV infection in these elderly subjects. Therefore, we recommend that patients of age 55 years and more should be included in trials of 
chronic hepatitis $\mathrm{C}$ treatment. For those groups of patients, risk-benefit of antiviral therapy should be assessed on an individual basis[26].

In the present study the age more than 55 years was an independent predictor of poor response (OR for sustained response of those aged more than 55years). It is not known whether the rate of response in persons more than 68 years of age is the same as or worse than that for persons 55-68 years of age. Nevertheless, the AASLD guideline does not stipulate an upper age limit for antiviral therapy[16], although, in practice, elderly patients are less considered and referred for treatment. We believe that therapy should be considered for patients up to the age of 68 years.

Funding: Non.

\section{Conflicts of interest: Non.}

Ethical approval: The protocol of the study was approved by the ethical committee of Faculty of Medicine, Zagazig University. Informed consents were obtained from all patients.

\section{REFERENCES}

1. McHutchison JG . Understanding hepatitis C. Am J Manag Care 2004 ; 10:21-29.

2. Mohamed MK . Epidemiology of HCV in Egypt 2004. The Afro-Arab Liver Journal 2004 ; 3: 4152.

3. Ebeid ME, Bakry KA . Cellular immune response to infection by different genotypes of hepatitis C virus. Indian J Clin Biochem. 2009 ; 24:234-40.

4. Armstrong GL, Alter MJ, McQuillan GM, Margolis HS.The past incidence of hepatitis C infection: implications for the future burden of chronic liver disease in the United States. Hematology 2000, 31 : 777-82.

5. Okayama A, Stuver SO, Tabor E, Tachibana N, Kohara M, Mueller NE, et al. Incident hepatitis C virus infection in a community-based population in Japan. J Viral Hepat 2002; 9: 43-51.

6. Guadagnino V, Stroffolini $\mathrm{T}$, Rapicetta $\mathrm{M}$, Costantino A, Kondili LA, Menniti-Ippolito F, et al. Prevalence, risk factors, and genotype distribution of hepatitis $\mathrm{C}$ virus infection in the general population: a community-based survey in southern Italy. Hematology 1997; 26: 1006-11.

7. Mindikoglu AL, Miller RR . Hepatitis C in the elderly: epidemiology, natural history, and treatment. Clin Gastroenterol Hepatol. 2009, 7(2) : 128-34.

8. Hoshida Y, Ikeda K, Kobayashi M, Suzuki Y, Tsubota A, Saitoh S, et al. Chronic liver disease in the extremely elderly of 80 years or more: clinical characteristics, prognosis and patient survival analysis. J Hepatol 1999.; 31(5):860-66

9. Sayed HA, El Araby A, Hamed R . Egypt's progress towards achieving the millennium development goals. United Nations Development Program, 2010.

10. Seeff LB . Natural history of chronic hepatitis C. Hematology 2002; 36(5): S35-46

11. Freeman AJ, Dore GJ, Law MG, Thorpe M, Von Overbeck J, Lloyd AR, et al. Estimating progression to cirrhosis in chronic hepatitis C virus infection. Hepatology 2001; 34(4):809-16

12. Watson JP, Brind AM, Chapman CE, Bates CL, Gould FK, Johnson SJ, et al. Hepatitis C virus: epidemiology, and genotypes in the north east of England. Gut 1996; 38:269-76

13. Soriano V, Núñez $M$, Sánchez-Conde $M$, Barreiro P, García-Samaniego J, MartínCarbonero L, et al. Response to interferon-based therapies in $\mathrm{HIV}$-infected patients with chronic hepatitis C due to genotype 4. Antivir Ther 2005; 10(1):167-70

14. Floreani A . Hepatitis C: Should antiviral therapy be offered to elderly patients? Nat Rev Gastroenterol Hepatol 2009; 6(9):503-4.

15. Sherman M, Shafran S, Burak K, Doucette K, Wong W, Girgrah N, et al. Management of chronic hepatitis C: consensus guidelines. Can J Gastroenterol. 2007; 21:25C-34C.

16. Kao JH, Lai MY, Chen PJ, Hwang LH, Chen DS . Clinical significance of serum hepatitis $\mathrm{C}$ virus titers in patients with chronic type $\mathrm{C}$ hepatitis. Am J Gastroenterol 1996; 91(3):506-10.

17. Marcus EL, Tur-Kaspa R . Chronic hepatitis C virus infection in older adults. Clin Infect Dis 2005; 41(11): 1606-12.

18. Poynard T, Ratziu V, Charlotte F, Goodman Z, McHutchison J, Albrecht J. Rates and risk factors of liver fibrosis progression in patients with chronic hepatitis C. J Hepatol 2001; 34(5):730-9.

19. Horiike N, Masumoto T, Nakanishi K, Michitaka $\mathrm{K}$, Kurose K, Ohkura I, et al. Interferon therapy for patients more than 60 years of age with chronic hepatitis C. J Gastroenterol Hepatol 1995; 10(3):246-9.

20. Wali M, Harrison RF, Gow PJ, Mutimer D. Advancing donor liver age and rapid fibrosis progression following transplantation for hepatitis C. Gut 2002; 51(2):248-52.

21. Marcus EL, TuiKaspa R . Viral hepatitis in older adults. J Am Geriatr Soc 1997; 45:755-63.

22. Alessi N, Freni MA, Spadaro A, Ajello A, Turiano S, Migliorato D ,et al . Efficacy of interferon treatment (IFN) in elderly patients with chronic hepatitis C. Infez Med 2003; 11:208-12.

23. Thabut D, Calvez SL, Thibault V. Hepatitis C in 2410 patients 65 years or older: a severe and neglected curable disease ? Hepatology 2003; 38(1): 424.

24. Monica F, Lirussi F, Nassuato G, Castelletto MR, Mottola A, Okolicsanyi L. Hepatitis C virus infection and related chronic liver disease in a resident elderly population: the Silea Study. $J$ Viral Hepat 1998; 5:345-51.

25. Seeff LB, Hollinger FB, Alter HJ, Wright EC, Cain CM, Buskell ZJ ,et al. Long-term mortality 
and morbidity of transfusion-associated non-A, non-B, and type $\mathrm{C}$ hepatitis: A National Heart, Lung, and Blood Institute collaborative study. Hepatology 2001 ;33(2):455-63.

26. Imai $Y$, Kasahara A, Tanaka H, Okanoue $T$, Hiramatsu N, Tsubouchi $\mathrm{H}$, et al .Interferon therapy for aged patients with chronic hepatitis $\mathrm{C}$ : improved survival in patients exhibiting a biochemical response. J Gastroenterol 2004; 39: 1069-77

27. Thabut D, Calvez SL, Thibault V. Hepatitis C in 2410 patients 65 years or older: a severe and neglected curable disease [abstract 549]? Hepatology 2003; 38(Suppl 1):424.

28. Armstrong GL, Simard EP, Wasley A, McQuillan GM, Kuhnert WL, Alter MJ. The prevalence of hepatitis $\mathrm{C}$ virus (HCV) infection in the United
States 1999-2002. Hepatology 2004; 40(1): 176A.

29. Manns MP, McHutchison JG, Gordon SC, Rustgi VK, Shiffman M, Reindollar $R$, et al . Peginterferon $\alpha-2 b$ plus ribavirin compared with interferon $\alpha$-2b plus ribavirin for initial treatment of chronic hepatitis $\mathrm{C}$ : a randomized trial. Lancet 2001; 358:958-65.

30. Fried MW, Shiffman ML, Reddy KR, Smith C, Marinos G, Gonçales FL, et al . Peginterferon $\alpha-2 a$ plus ribavirin for chronic hepatitis $\mathrm{C}$ virus infection. N Engl J Med 2002; 347: 975-82.

31. Nudo CG, Gupta S, Alpert E, Wong P, Hilzenrat $\mathrm{N}$, Deschenes $\mathrm{M}$. Elderly patients are at greater risk of cytopenia during antiviral therapy for hepatitis C [abstract 48]. Can J Gastroenterol 2004; 18(Suppl A) : 83. 